\title{
Early low cerebral blood flow and high cerebral lactate: prediction of delayed cerebral ischemia in subarachnoid hemorrhage
}

\author{
Elham Rostami, MD, PhD, ${ }^{1}$ Henrik Engquist, MD, ${ }^{1,2}$ Timothy Howells, PhD, ${ }^{1}$ \\ Ulf Johnson, MD, PhD, ${ }^{1,3}$ Elisabeth Ronne-Engström, MD, PhD, ${ }^{1}$ Pelle Nilsson, MD, PhD, ${ }^{1}$ \\ Lars Hillered, MD, PhD, ${ }^{1}$ Anders Lewén, MD, PhD, ${ }^{1}$ and Per Enblad, MD, PhD ${ }^{1}$
}

${ }^{1}$ Section of Neurosurgery, Department of Neuroscience, ${ }^{2}$ Anesthesiology and Intensive Care, Department of Surgical Sciences, and ${ }^{3}$ Department of Surgical Sciences and Radiology, Uppsala University, Uppsala, Sweden

\begin{abstract}
OBJECTIVE Delayed cerebral ischemia ( $\mathrm{DCl})$ following subarachnoid hemorrhage $(\mathrm{SAH})$ is one of the major contributors to poor outcome. It is crucial to be able to detect early signs of $\mathrm{DCl}$ to prevent its occurrence. The objective of this study was to determine if low cerebral blood flow (CBF) measurements and pathological microdialysis parameters measured at the bedside can be observed early in patients with SAH who later developed DCI.
\end{abstract}

METHODS The authors included 30 patients with severe SAH. The CBF measurements were performed at Day 0-3 after disease onset, using bedside xenon-CT. Interstitial glucose, lactate, pyruvate, glycerol, and glutamate were measured using microdialysis.

RESULTS Nine of 30 patients developed DCl. Patients with DCl showed significantly lower global and regional CBF, and lactate was significantly increased in these patients. A high lactate/pyruvate ratio was also detected in patients with $\mathrm{DCl}$.

CONCLUSIONS Early low CBF measurements and a high lactate and lactate/pyruvate ratio may be early warning signs of the risk of developing $\mathrm{DCl}$. The clinical value of these findings needs to be confirmed in larger studies.

https://thejns.org/doi/abs/10.3171/2016.11.JNS161140

KEY WORDS xenon-CT; lactate; CBF; cerebral blood flow; lactate/pyruvate ratio; SAH; subarachnoid hemorrhage; $\mathrm{DCl}$; delayed cerebral ischemia; vasospasm; vascular disorders

$\mathrm{P}$ ATIENTS with aneurysmal subarachnoid hemorrhage (SAH) suffer high rates of mortality and morbidity as a result of the primary hemorrhage and secondary injuries. Whereas the primary hemorrhagic injury is difficult to prevent, the secondary injuries may be prevented if detected in time. Hemodynamic and metabolic disturbances have been detected in the acute stage of SAH in both animals and humans. ${ }^{7,13}$ These early disturbances make the brain vulnerable to secondary injuries. Secondary ischemic brain injury is one of the major contributors to poor outcome. Although cerebral vasospasm has been considered to be the major instigator of secondary ischemia, the discrepancy between angiographic findings and the development of clinical signs ${ }^{15,27}$ suggests additional contributing factors. It is now believed that the causes are multifactorial and may involve endothelial dysfunction, blood-brain barrier disruption, cortical spreading depolarizations, microvascular thrombosis, and failure of cerebral autoregulation. Current guidelines for the critical care management of patients with SAH recommend the use of the term "delayed cerebral ischemia" (DCI) for this secondary brain injury, which is characterized by focal neurological impairment, decrease of Glasgow Coma Scale (GCS) score, and/or radiological signs of ischemia or infarction. ${ }^{5}$

To prevent DCI it would be ideal to detect early signs of hemodynamic or metabolic disturbances at the bedside. This would also help in identifying patients who are vul-

ABBREVIATIONS CBF = cerebral blood flow; $\mathrm{CPP}=$ cerebral perfusion pressure; $\mathrm{DCl}=$ delayed cerebral ischemia; $\mathrm{GCS}, \mathrm{GCS}-\mathrm{M}=\mathrm{Glasgow}$ Coma Scale, $\mathrm{GCS}-\mathrm{motor}$; GOSE = Glasgow Outcome Scale-Extended; ICP = intracranial pressure; $\mathrm{L} / \mathrm{P}=$ lactate/pyruvate; $\mathrm{MD}=$ microdialysis; NIC = neurointensive care; $\mathrm{ROI}=$ region of interest; $\mathrm{SAH}=$ subarachnoid hemorrhage; $\mathrm{Xe}-\mathrm{CT}=$ xenon-CT.

SUBMITTED May 3, 2016. ACCEPTED November 17, 2016.

INCLUDE WHEN CITING Published online June 2, 2017; DOI: 10.3171/2016.11.JNS161140. 
nerable to secondary brain insults in general. Xenon-CT (Xe-CT) has been shown to be feasible and valuable in detecting early signs of vasospasm and/or low cerebral blood flow (CBF) and to predict development of infarction..$^{28,36}$ Microdialysis (MD) has been used extensively in patients with $\mathrm{SAH}$, with promising results. ${ }^{9}$ We have previously reported on the feasibility of combining bedside Xe-CT with MD in patients suffering an SAH. ${ }^{17}$ The objective of the current study was to investigate whether early bedside $\mathrm{CBF}$ measurements in combination with MD metabolites could differentiate between patients with SAH who develop DCI and those who do not.

\section{Methods}

\section{Study Population and Design}

Many details of the following protocols were first reported by us elsewhere. ${ }^{16}$ Patients suffering an SAH were included in the study if they had undergone intracerebral MD studies and were examined with Xe-CT at Day 0-3 following symptom onset. This time period for Xe-CT was chosen because vasospasm and DCI are almost never seen before Day 3 post-SAH. ${ }^{1,30,32}$ The Xe-CT studies required mechanical ventilation for administration of the xenon gas, and MD was only used in patients who received a ventriculostomy (i.e., patients with more severe SAH were selected). Xenon-CT scanning and insertion of an MD catheter were not always possible for logistical reasons.

Patients with a preexisting neurological deficit or an SAH resulting from trauma or arteriovenous malformation were excluded. The SAH was verified by CT scanning, and the aneurysm was visualized by $\mathrm{CT}$ angiography or digital subtraction angiography. All patients included in the study were enrolled within 24 hours of the onset of SAH.

Clinical data were collected from the electronic records and the neurointensive care (NIC) unit database for patients with SAH. The Fisher grade was assessed by the responsible neurosurgeon at admission. A neuroradiologist examined the $\mathrm{CT}$ scans at discharge to determine whether there were signs of ischemia or infarction. A nurse assessed the Glasgow Outcome Scale-Extended (GOSE) score at the 1-year follow-up. ${ }^{10}$

\section{Neurointensive Care}

All patients suffering an SAH were managed according to a standardized protocol. ${ }^{18}$ All unconscious patients and those with clinical and radiological signs of intracranial hypertension receive a ventriculostomy. If the intracranial pressure (ICP) is $>20 \mathrm{~mm} \mathrm{Hg}$, the drainage system is opened and CSF is drained against a pressure level of 15 $\mathrm{mm} \mathrm{Hg}$. Identified aneurysms are treated early by endovascular coiling or surgical clipping. All patients receive $0.2 \mathrm{mg} / \mathrm{ml}$ nimodipine (Nimotop, Bayer AB). If the blood pressure allows it, the goal rate is $10 \mathrm{ml} /$ hour. A daily fluid substitution of $2.5 \mathrm{~L}$ is used before treatment of the aneurysm, and $3.0 \mathrm{~L}$ is administered after the treatment. The volume status is maintained by fluid administration in the higher normal range, with addition of albumin infusion (Flexbumin, $200 \mathrm{mg} / \mathrm{ml}$; Baxter AG) if needed, and patients are monitored by central venous pressure mea- surement, clinical evaluation, and rigorous fluid balance calculation. Hypotension is treated first with crystalloid solutions and albumin 20\% and second with dobutamine if needed. The goal is to keep the cerebral perfusion pressure $(\mathrm{CPP})>60 \mathrm{~mm} \mathrm{Hg}$.

As a part of our protocol a wake-up test is performed 6 times per 24 hours. ${ }^{26}$ The patients received the diagnosis of DCI when delayed ischemic neurological deterioration and/or deficits occurred that could not be explained by other reasons. The DCI was treated with hypertension, hypervolemia, and hemodilution therapy (triple- $\mathrm{H}$ therapy) by the administration of $500 \mathrm{ml} /$ day dextran 40 solutions (Rheomacrodex, $100 \mathrm{mg} / \mathrm{ml}$; Meda AB) and albumin 100 $\mathrm{ml} \times 2(200 \mathrm{mg} / \mathrm{ml}$; Baxter Medical AB).

\section{Cerebral Blood Flow Measurements}

Xenon-CT is performed at the bedside in the NIC unit, by using a mobile CT scanner (CereTom, Neurologica), at Day 0-3 after admission in all patients with SAH who are receiving mechanical ventilation. The CBF measurements are done according to the principles described by Yonas et al. ${ }^{12,33-35}$ The xenon gas is radiopaque, highly lipid soluble, and capable of crossing the blood-brain barrier. The Kety-Schmidt equation is applied to measure regional and global CBF. ${ }^{11}$ Stable xenon, at a concentration of $28 \%$, is administered to the patient's breathing circuit for approximately 4 minutes, using the Enhancer 3000 and the computer software designed for the purpose (Diversified Diagnostic Products, Inc.). During the xenon inhalation, CT scans are obtained. The xenon delivery and the CT scans are synchronized by the computer software, and the resulting radiological tissue enhancement of the xenon wash-in enables CBF (in $\mathrm{ml} / 100 \mathrm{~g} / \mathrm{min}$ ) to be calculated and plotted as colored maps in scans at 4 different levels of the brain (8 scans per level, 2 baseline and 6 enhanced, with 10-mm spacing).

Analysis of CBF measurements has been previously described in detail. ${ }^{17}$ The mean blood flow in each of 20 evenly distributed cortical regions of interest (ROIs) is calculated for each level, and the global CBF is given as a mean of all 4 levels. The tip of the MD catheter was identified on the structural CT scans, and an ROI was drawn manually (diameter $3 \mathrm{~cm}$ ) for the corresponding area around the MD catheter on the CBF scans (Fig. 1). Regions with CTdefined hematoma or artifact were noted and excluded.

\section{Cerebral MD}

The cerebral MD technique in the NIC unit has previously been extensively used and described..$^{8,29}$ The intracerebral MD catheter was placed in the right frontal lobe cortex through a separate bur hole, anterior to the ventricular drain. For intracerebral MD monitoring, we used a No. 70 brain MD catheter (M Dialysis AB) with a membrane length of $10 \mathrm{~mm}$ and a membrane cutoff of 20,000 D. The catheters were perfused with artificial CSF $(\mathrm{NaCl}$ $147 \mathrm{mmol} / \mathrm{L}, \mathrm{KCl} 2.7 \mathrm{mmol} / \mathrm{L}, \mathrm{CaCl}_{2} 1.2 \mathrm{mmol} / \mathrm{L}, \mathrm{MgCl}_{2}$ $0.85 \mathrm{mmol} / \mathrm{L}$ ) (Perfusion Fluid CNS, M Dialysis AB).

The perfusion rate was $0.3 \mu \mathrm{l} /$ minute using a microinjection pump (CMA-106, M Dialysis AB). The MD urea was monitored to validate catheter performance. ${ }^{16}$ The 

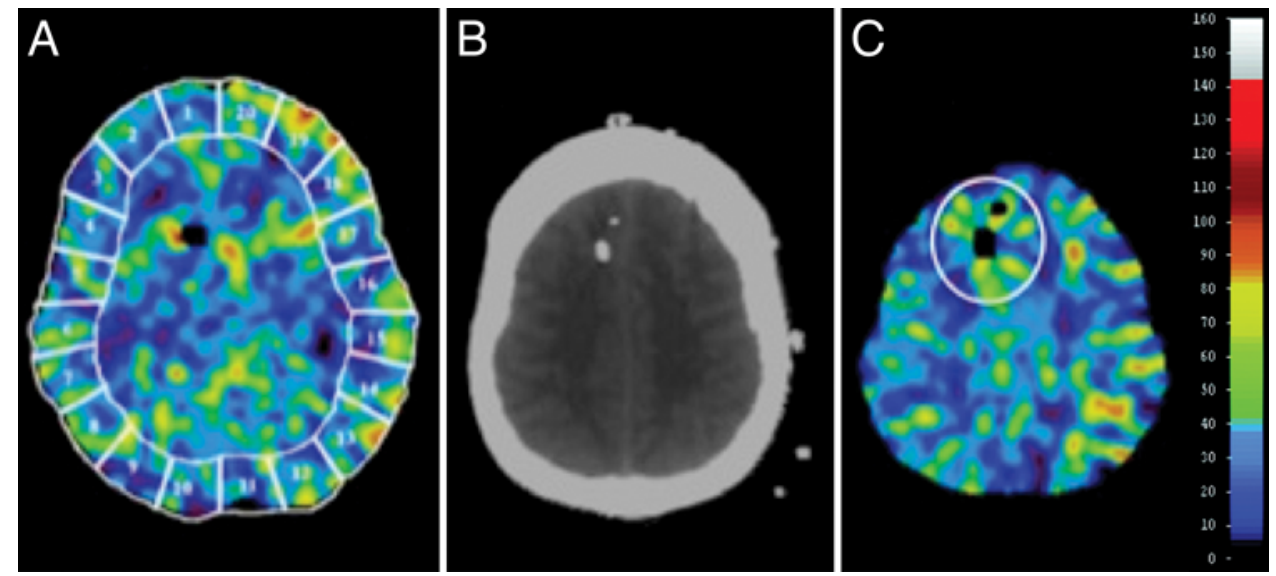

FIG. 1. Following xenon delivery, tissue enhancement of the xenon wash-in enabled CBF to be calculated and plotted as colored maps (panels $A$ and $C$ ). Twenty cortical ROls were used for CBF calculation (A). Conventional CT images were obtained and the location of the MD catheter was identified (B). The CBF around the MD catheter was calculated by drawing an ROI manually (C). Scale for CBF is given on the right side of panel $\mathrm{C}$ (in $\mathrm{ml} / 100 \mathrm{~g} / \mathrm{min}$ ).

MD samples were collected on an hourly basis. The MD samples for the 3-hour period before and the 3-hour period after the Xe-CT examination were used for analysis. Interstitial glucose, lactate, pyruvate, glutamate, glycerol, and urea were analyzed enzymatically using a CMA 600 analyzer or ISCUS Clinical Microdialysis Analyzer (M Dialysis AB).

\section{Statistical Analysis}

All analyses were performed using SPSS Statistics for Macintosh, version 23.0 (IBM Corp.). To assess the normality of the data set, the skewness and kurtosis of the distribution were analyzed. Results are expressed as the mean \pm SD. A $p$ value of $<0.05$ was considered statistically significant.

\section{Ethics Approvals}

Uppsala University's regional ethical review board for clinical research granted permission to undertake the study. Written informed consent was obtained from all patients or their proxy for study participation. The study was also approved by the local radiation safety authority.

\section{Results}

A total of 401 patients with SAH (282 with aneurysmal $\mathrm{SAH}$ ) were admitted during the period between October 2012 and May 2015. Sixty-four patients underwent Xe-CT examination, of whom 30 also received an MD catheter and were included in this study. There were no adverse effects associated with Xe-CT examinations and no complications were caused by MD catheter insertion.

The clinical characteristics of the 30 patients included in the study as well as the aneurysm locations are given in Table 1 . The majority of the patients had aneurysms in the anterior circulation. Physiological conditions before and after the Xe-CT examinations are presented in Table 2.

\section{Delayed Cerebral Ischemia}

Nine of 30 patients developed DCI. There was no sig- nificant difference in age between the DCI and no-DCI groups, and neither were there any differences in CT Fisher scores, Hunt and Hess grades, GCS-motor (GCS-M) scores at admission, or GCS-M scores at discharge (Table 3 ). The sedation and physiological conditions during $\mathrm{Xe}-$ CT were also similar (see Table 2).

\section{Cerebral Blood Flow Measurements}

The mean global CBF for all patients was $33.3 \pm 13.5$ $\mathrm{ml} / 100 \mathrm{~g} / \mathrm{min}$ (range $13.7-73.9 \mathrm{ml} / 100 \mathrm{~g} / \mathrm{min}$ ). The mean $\mathrm{CBF}$ around the MD catheter for all patients was $30.4 \pm$ $12.6 \mathrm{ml} / 100 \mathrm{~g} / \mathrm{min}$ (range $11-56.9 \mathrm{ml} / 100 \mathrm{~g} / \mathrm{min}$ ). There was no significant difference between the global CBF and $\mathrm{CBF}$ around the MD catheter $(\mathrm{p}=0.39)$. There was a positive correlation between the global $\mathrm{CBF}$ and the $\mathrm{MD} \mathrm{CBF}$ $(\mathrm{r}=0.924, \mathrm{p}<0.0001)$.

Patients who went on to develop DCI had significantly lower global CBF values than patients who did not (23.7 $\pm 6.7 \mathrm{ml} / 100 \mathrm{~g} / \mathrm{min}$ [range $13.7-34.5 \mathrm{ml} / 100 \mathrm{~g} / \mathrm{min}$ ] and $37.5 \pm 13.7 \mathrm{ml} / 100 \mathrm{~g} / \mathrm{min}$ [range $21.5-73.9 \mathrm{ml} / 100 \mathrm{~g} / \mathrm{min}$ ], respectively; $p=0.005$ ). Illustrative cases are presented in Fig. 2. Patients who developed DCI also had significantly lower values for $\mathrm{CBF}$ around the MD catheter than did no-DCI patients $(21.4 \pm 5.3 \mathrm{ml} / 100 \mathrm{~g} / \mathrm{min}$ [range 11-29.1 $\mathrm{ml} / 100 \mathrm{~g} / \mathrm{min}]$ in the DCI group and $34.4 \pm 12.8 \mathrm{ml} / 100 \mathrm{~g} /$ min [range $18.9-56.9 \mathrm{ml} / 100 \mathrm{~g} / \mathrm{min}$ ] in the no-DCI group; $\mathrm{p}=0.007$ ) (Fig. 3).

\section{Microdialysis Parameters}

The mean values and ranges of glucose, lactate, pyruvate, glycerol, glutamate, and the lactate/pyruvate (L/P) ratio for all patients are given in Table 4 . The $\mathrm{L} / \mathrm{P}$ ratio was higher in the DCI group than in the no-DCI group (32.1 \pm 16 vs $24.9 \pm 8.1)$, but the difference was not statistically significant $(\mathrm{p}=0.065)$. Lactate was significantly higher in the DCI group than in the no-DCI group (4.8 \pm $2.2 \mathrm{mmol} / \mathrm{L}$ and $3.4 \pm 1.7 \mathrm{mmol} / \mathrm{L}$, respectively; $\mathrm{p}=0.029)$ (Fig. 4). Glucose did not show any significant difference between the DCI and the no-DCI group $(2.1 \pm 1.2 \mathrm{mmol} / \mathrm{L}$ and $2.3 \pm 1.1 \mathrm{mmol} / \mathrm{L}$, respectively) (Fig. 5). There also 
TABLE 1. Demographic and clinical characteristics in 30 patients with severe SAH

\begin{tabular}{|c|c|}
\hline Variable & Value \\
\hline Age in yrs (range) & $58.9(28-84)$ \\
\hline Female/male & $25 / 5$ \\
\hline Coiling/clipping & $25 / 4$ \\
\hline \multicolumn{2}{|l|}{ GCS-M score on admission } \\
\hline 1 & 1 \\
\hline 2 & 0 \\
\hline 3 & 2 \\
\hline 4 & 2 \\
\hline 5 & 10 \\
\hline 6 & 15 \\
\hline \multicolumn{2}{|l|}{ GCS-M score at discharge } \\
\hline 1 & 1 \\
\hline 2 & 1 \\
\hline 3 & 0 \\
\hline 4 & 6 \\
\hline 5 & 4 \\
\hline 6 & 18 \\
\hline \multicolumn{2}{|l|}{ Hunt \& Hess grade } \\
\hline I & 2 \\
\hline II & 6 \\
\hline III & 9 \\
\hline IV & 11 \\
\hline V & 2 \\
\hline \multicolumn{2}{|l|}{ Fisher grade } \\
\hline $1-2$ & 0 \\
\hline 3 & 8 \\
\hline 4 & 22 \\
\hline \multicolumn{2}{|l|}{ Aneurysm location } \\
\hline Anterior communicating artery & 9 \\
\hline Internal carotid artery & 4 \\
\hline Posterior communicating artery & 5 \\
\hline Middle cerebral artery & 6 \\
\hline Anterior choroidal artery & 1 \\
\hline Posterior cerebral artery & 1 \\
\hline Basilar artery & 1 \\
\hline Posterior inferior cerebellar artery & 2 \\
\hline Unknown & 1 \\
\hline
\end{tabular}

Values are number of patients unless otherwise indicated.

were no significant differences between the groups for pyruvate, glycerol, or glutamate. However, in both the DCI and the no-DCI groups there was very large within-group variation in glutamate between the patients.

\section{Cerebral Blood Flow and Lactate}

In the group of patients who later developed DCI, all had global CBF values $<28 \mathrm{ml} / 100 \mathrm{~g} / \mathrm{min}$, except 2 patients with global CBF of $32.9 \mathrm{ml} / 100 \mathrm{~g} / \mathrm{min}$ and $34.5 \mathrm{ml} / 100 \mathrm{~g} /$ min, respectively (CBF-MD 29.1 and $26.8 \mathrm{ml} / 100 \mathrm{~g} / \mathrm{min}$, respectively). One of these 2 patients had a lactate value of
TABLE 2. Physiological parameters before and after Xe-CT measurements in all patients, in patients who developed $\mathrm{DCl}$, and in those who did not

\begin{tabular}{|c|c|c|c|c|}
\hline Parameter & All & No DCl & $\mathrm{DCl}$ & $\begin{array}{l}\text { p Value } \\
\text { (no DCl } \\
\text { vs DCl) }\end{array}$ \\
\hline \multicolumn{5}{|l|}{ Before Xe-CT } \\
\hline $\mathrm{Po}_{2}(\mathrm{kPa})$ & $13.3 \pm 2.8$ & $13.4 \pm 3.0$ & $13.0 \pm 2.2$ & 0.74 \\
\hline $\mathrm{PcO}_{2}(\mathrm{kPa})$ & $5.1 \pm 0.4$ & $5.0 \pm 0.3$ & $5.1 \pm 0.5$ & 0.69 \\
\hline $\mathrm{FiO}_{2}(\%)$ & $39.3 \pm 10.3$ & $40.5 \pm 10.3$ & $36.6 \pm 10.3$ & 0.36 \\
\hline $\mathrm{MAP}(\mathrm{mm} \mathrm{Hg})$ & $94.1 \pm 14.1$ & $90.9 \pm 10.0$ & $101.8 \pm 19.6$ & 0.07 \\
\hline ICP (mm Hg) & $17.0 \pm 5.0$ & $17.0 \pm 5.6$ & $16.9 \pm 3.6$ & 0.95 \\
\hline $\mathrm{CPP}(\mathrm{mm} \mathrm{Hg})$ & $77.6 \pm 15.5$ & $73.7 \pm 10.4$ & $86.6 \pm 21.5$ & 0.040 \\
\hline \multicolumn{5}{|l|}{ After Xe-CT } \\
\hline $\mathrm{Po}_{2}(\mathrm{kPa})$ & $13.6 \pm 3.0$ & $13.9 \pm 3.4$ & $12.9 \pm 2.0$ & 0.42 \\
\hline $\mathrm{PcO}_{2}(\mathrm{kPa})$ & $5.2 \pm 0.5$ & $5.3 \pm 0.5$ & $5.2 \pm 0.5$ & 0.67 \\
\hline $\mathrm{FiO}_{2}(\%)$ & $39.6 \pm 10.1$ & $40.7 \pm 10.2$ & $37.2 \pm 10.0$ & 0.40 \\
\hline MAP $(\mathrm{mm} \mathrm{Hg})$ & $90.5 \pm 11.8$ & $88.4 \pm 11.7$ & $95.3 \pm 11.3$ & 0.17 \\
\hline ICP (mm Hg) & $17.5 \pm 4.7$ & $18.0 \pm 5.2$ & $16.2 \pm 3.2$ & 0.37 \\
\hline $\mathrm{CPP}(\mathrm{mm} \mathrm{Hg})$ & $76.9 \pm 13.1$ & $72.4 \pm 10.9$ & $87.1 \pm 12.6$ & 0.006 \\
\hline
\end{tabular}

$\mathrm{FiO}_{2}=$ fraction of inspired oxygen; MAP = mean arterial pressure; $\mathrm{PCO}_{2}=$ partial pressure of carbon dioxide; $\mathrm{PO}_{2}=$ partial pressure of oxygen.

Values are expressed as the mean \pm SD. Boldface type indicates statistical significance.

$2.6 \mathrm{mmol} / \mathrm{L}$, and all other patients in the group who developed DCI had values $\geq 3.7 \mathrm{mmol} / \mathrm{L}$ (Table 5).

In the 21 patients who did not develop DCI, 3 patients had a global CBF of 21.5-26.7 ml/100 g/min (CBF-MD $18.9-23 \mathrm{ml} / 100 \mathrm{~g} / \mathrm{min}$ ), and all the other patients had values $>28 \mathrm{ml} / 100 \mathrm{~g} / \mathrm{min}$. The lactate levels for these $3 \mathrm{pa}-$ tients were $2.5-3.5 \mathrm{mmol} / \mathrm{L}$. Three other patients in the group who did not develop DCI had high lactate values (5.8-7.6 $\mathrm{mmol} / \mathrm{L})$, and these patients had a high global CBF of $35-41 \mathrm{ml} / 100 \mathrm{~g} / \mathrm{min}$.

\section{Glasgow Outcome Scale-Extended Scores and CT Scans}

At 1-year follow-up 5 patients had died, and 2 of these patients were in the DCI group. Both groups had patients with good recovery at 1-year follow-up, and no significant difference was observed between the groups. The frequency of each GOSE score for both groups is given in Table 6 . The GOSE scores for patients who later developed DCI are given in Table 5.

TABLE 3. Results of clinical data comparing patients who later developed $\mathrm{DCl}$ and those who did not

\begin{tabular}{lccc}
\hline \multicolumn{1}{c}{ Parameter } & $\mathrm{No} \mathrm{DCl}$ & $\mathrm{DCl}$ & $\mathrm{p} \mathrm{Value}$ \\
\hline Age in yrs & $58.5(28-84)$ & $58.5(48-75)$ & 0.81 \\
\hline GCS-M score at admission & $4.9(1-6)$ & $5.6(4-6)$ & 0.06 \\
\hline GCS-M score at discharge & $5.3(3-6)$ & $5.3(4-6)$ & 0.71 \\
\hline Fisher grade & $3.8(3-4)$ & $3.6(3-4)$ & 0.22 \\
\hline Hunt \& Hess grade & $3.4(1-5)$ & $2.9(2-4)$ & 0.12 \\
\hline
\end{tabular}

Values are expressed as the mean (range). 

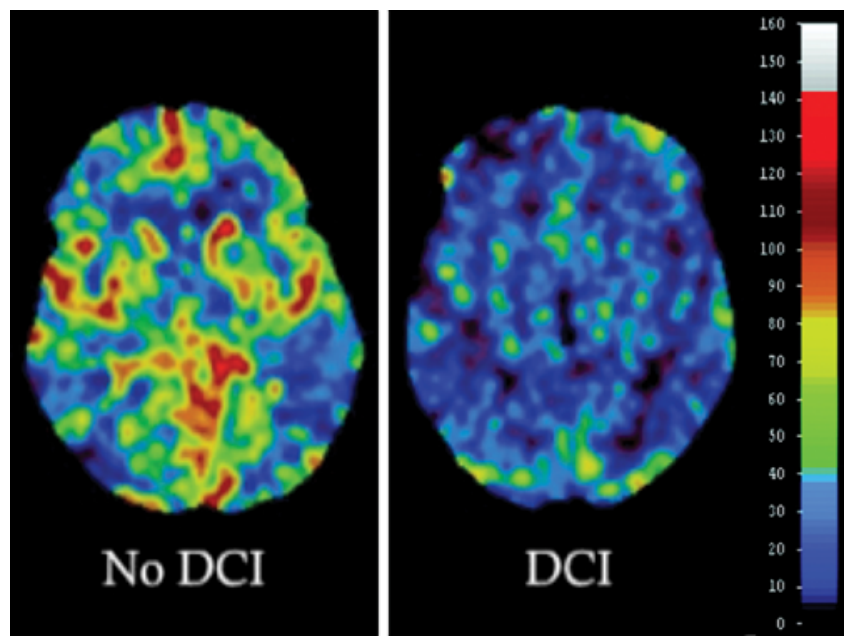

FIG. 2. Xenon-CT scans of illustrative cases. Left: A patient who did not develop DCl. Right: A patient with low global CBF who later developed $\mathrm{DCl}$. Scale for $\mathrm{CBF}$ is given on the right side of the right panel (in $\mathrm{ml} / 100 \mathrm{~g} / \mathrm{min}$ ).

The CT scans at discharge were evaluated, and in the no-DCI group, 4 patients had infarction in 1 hemisphere and 2 patients had it in both hemispheres. No signs of infarction were detected at this time point in the remaining patients. In the group of patients who developed DCI, 1 patient had signs of cortical infarct in 1 hemisphere, 4 patients had it in both hemispheres, and no infarction could be detected in the remaining 4 patients in this group (Table 5).

\section{Discussion}

We present results in 30 patients suffering an SAH who had MD monitoring of cerebral metabolism and who underwent CBF measurements at bedside, in which Xe-CT was used. There were no complications associated with the monitoring, and we found the combination of these methods feasible. The results represent values obtained in the first days after hemorrhage (Days $0-3$ ), and before any clinical signs appeared pathological values were documented in patients who developed DCI. Nine patients who developed DCI had significantly higher lactate and lower $\mathrm{CBF}$. They also tended to have a higher $\mathrm{L} / \mathrm{P}$ ratio, although the increase was borderline significant. These results confirm our previous findings that low $\mathrm{CBF}$ is associated with

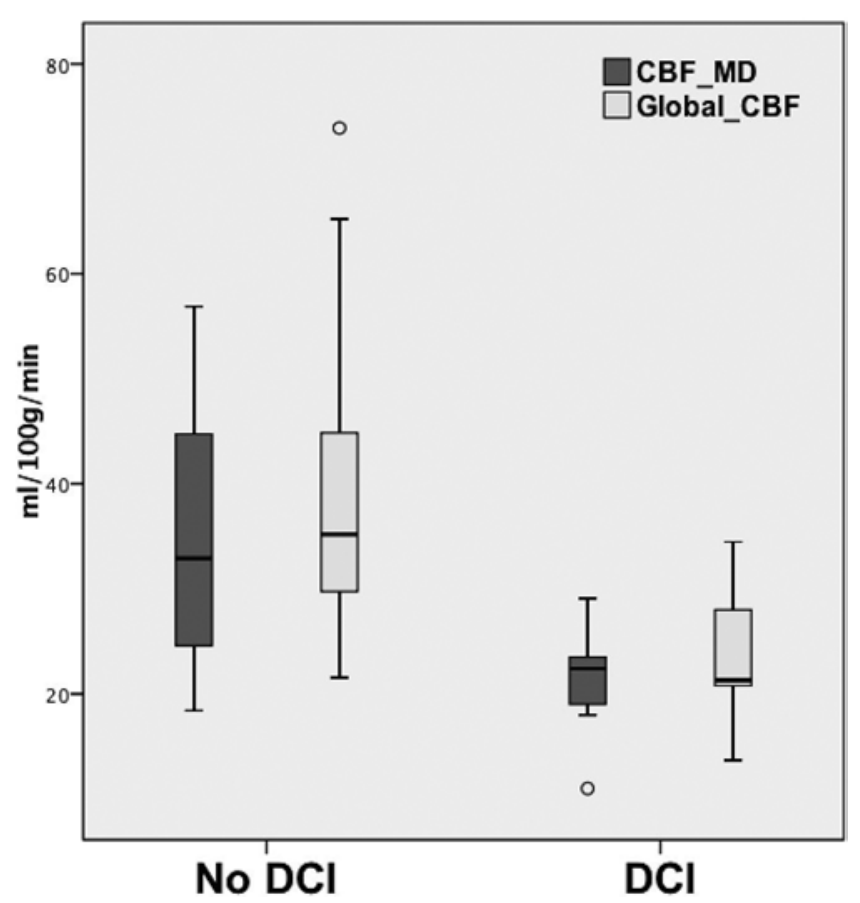

FIG. 3. Box plot of global $\mathrm{CBF}$ and $\mathrm{CBF}$ in the region around the MD catheter (CBF_MD) in patients who later developed $\mathrm{DCl}$ and those who did not. The difference between the groups was significant in both measurements.

disturbed energy metabolism, and that low $\mathrm{CBF}$ as well as disturbed energy metabolism according to MD may identify patients who will develop DCI before clinical signs appear. ${ }^{17}$ Larger studies are required to assess the clinical value of these findings.

There are few reported studies that combined CBF measurements with MD in patients with SAH. The first study was performed by Enblad et al., who used PET and MD in 6 patients with SAH. These investigators detected regional ischemia by PET and found that lactate, $\mathrm{L} / \mathrm{P}$ ratio, and glutamate had the highest sensitivity for detecting ischemia. ${ }^{6}$ In 2 additional small studies, which included 13 and 15 patients, respectively, PET was combined with MD, and pathological MD parameters were found to be associated with low regional CBF values, ${ }^{21,22}$ with the strongest association being between glutamate and low CBF, followed by glycerol. The L/P ratio was the most sensitive and specific parameter for detecting a longer period of is-

TABLE 4. Microdialysis parameters in all patients, in patients who developed DCl, and in those who did not

\begin{tabular}{lcccc}
\hline \multicolumn{1}{c}{ Parameter } & All & No DCl & $\mathrm{DCl}$ & $\mathrm{p} \mathrm{Value}$ \\
\hline Glucose $(\mathrm{mmol} / \mathrm{L})$ & $2.3(0.5-5.3)$ & $2.3(0.5-5.3)$ & $2.1(0.6-4.2)$ & 0.98 \\
\hline Lactate $(\mathrm{mmol} / \mathrm{L})$ & $3.9(1.4-10.4)$ & $3.4(1.4-7.6)$ & $4.8(2.5-10.4)$ & 0.029 \\
\hline Pyruvate $(\mu \mathrm{mol} / \mathrm{L})$ & $143.6(66.7-249.4)$ & $136.1(66.7-249.4)$ & $156.4(108.7-223.1)$ & 0.20 \\
\hline Glycerol $(\mu \mathrm{mol} / \mathrm{L})$ & $147.5(18-577)$ & $129(18-475)$ & $167.8(28-577)$ & 0.48 \\
\hline Glutamate $(\mu \mathrm{mol} / \mathrm{L})$ & $32.2(0.2-254)$ & $33.5(0.2-254)$ & $23.9(1.4-66.8)$ & 0.86 \\
\hline L/P ratio & $27.6(15.2-71.2)$ & $24.9(15.2-47.8)$ & $32.1(16.6-71.2)$ & 0.065 \\
\hline
\end{tabular}

Microdialysis values are expressed as the mean (range) in all patients. The p values are calculations made to compare the difference between patients who later developed $\mathrm{DCl}$ and those who did not. Boldface type indicates statistical significance. 

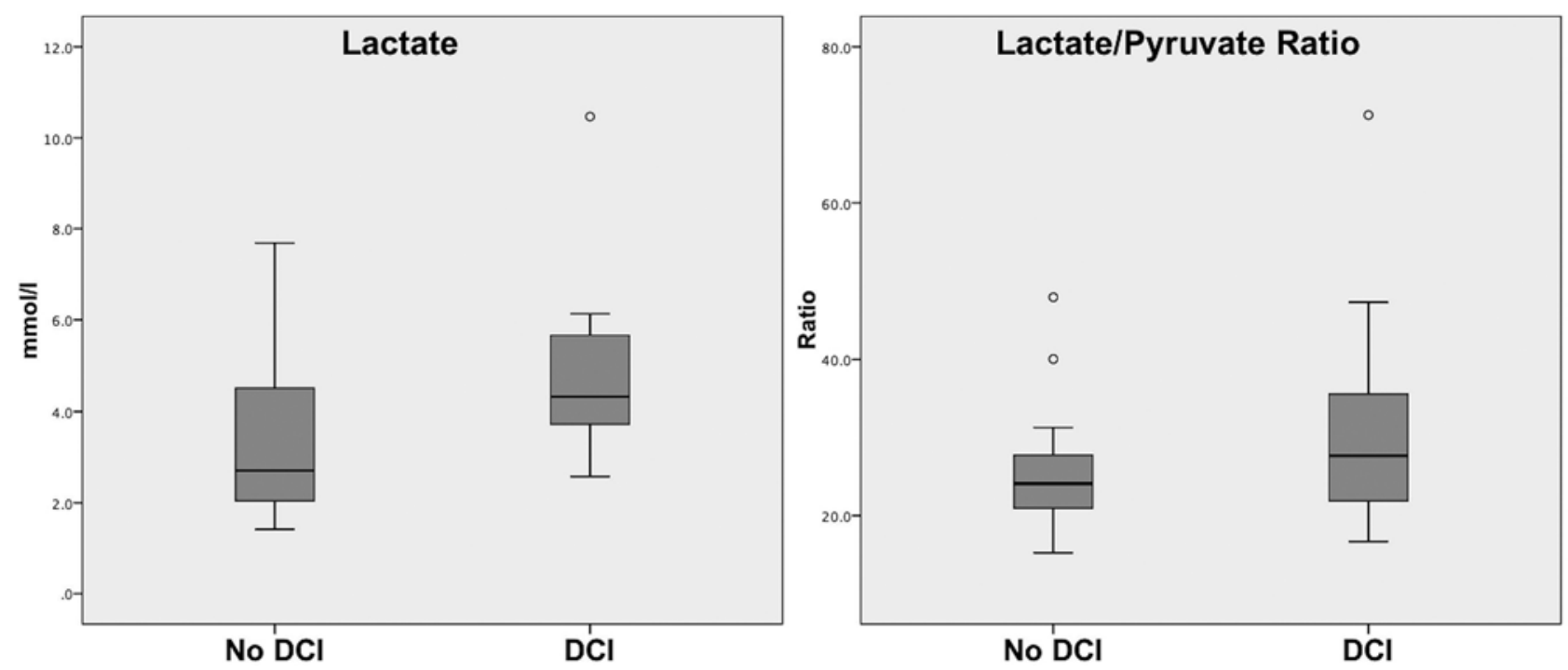

FIG. 4. Box plots of microdialysate lactate and L/P ratio in patients who later developed $\mathrm{DCl}$ and those who did not. Lactate was significantly higher in patients who later developed DCl.

chemia. In symptomatic patients significantly higher L/P ratio and levels of lactate and glutamate were seen. ${ }^{22}$ The results from these studies confirm our findings that a high $\mathrm{L} / \mathrm{P}$ ratio and high lactate are associated with reduction of $\mathrm{CBF}$, and that patients with signs of DCI show high lactate and $\mathrm{L} / \mathrm{P}$ ratio. In contrast to our current results, in both studies glutamate was found to be a sensitive marker of ischemia. This could be partly explained by the differences between the studies, such as number of patients, time period of MD analyzed, and the location of the MD catheter.

In the current study we included more patients, and MD values at the time of CBF measurements were chosen. Enblad et al. analyzed MD with a flow rate of $2 \mu \mathrm{l} /$ minute every 10-15 minutes during PET, ${ }^{6}$ whereas Sarrafzadeh et al. analyzed MD hourly with a flow of $0.3 \mu \mathrm{l} /$ minute, and used a mean of 3 days for their analysis. ${ }^{23}$ Furthermore, Sarrafzadeh et al. placed the MD catheter in the vascular territory at risk for developing vasospasms, whereas we placed the MD catheter in the right frontal lobe. The glutamate levels at the time of CBF measurements in our study were highly variable both in the DCI group and the no-DCI group. There is also a wide variation in the time of CBF measurements in previous studies, with a range of 2-24 days after the hemorrhage. We used the time frame of $0-3$ days, the time period before the occurrence of vasospasm. ${ }^{32}$

One study combined Xe-CT and MD in 16 patients with SAH during Days 3-10 and could not find any correlation between $\mathrm{L} / \mathrm{P}$ ratio and clinical status. ${ }^{4}$

Several studies have used MD without CBF measurements in patients with SAH and reported on high lactate levels ${ }^{25}$ and $\mathrm{L} / \mathrm{P}$ ratio $^{3,19,20,23,24}$ indicating ischemia, and this was associated with poor outcome. Sarrafzadeh et al. detected significantly higher lactate concentrations on Days 1-8 after SAH in patients who later developed DCI, and a higher L/P ratio on Days 3-8 than in asymptomatic patients. ${ }^{23}$ Interestingly, the majority of patients who developed DCI (83\%) showed a characteristic metabolic

TABLE 5. Clinical characteristics and CBF and MD values for each patient who developed DCI

\begin{tabular}{|c|c|c|c|c|c|c|c|c|c|c|c|c|}
\hline \multirow[b]{2}{*}{$\begin{array}{l}\text { Case } \\
\text { No. }\end{array}$} & \multirow[b]{2}{*}{$\begin{array}{l}\text { Fisher } \\
\text { Grade }\end{array}$} & \multirow[b]{2}{*}{$\begin{array}{c}\text { Hunt \& Hess } \\
\text { Grade }\end{array}$} & \multirow[b]{2}{*}{ GOSE* $^{*}$} & \multirow[b]{2}{*}{$\begin{array}{c}\text { CT } \\
\text { Scant }\end{array}$} & \multicolumn{2}{|c|}{ CBF Values (ml/100 g/min) } & \multicolumn{6}{|c|}{ Cerebral MD Values } \\
\hline & & & & & MD & Global & $\begin{array}{l}\text { Glucose } \\
\text { (mmol/L) }\end{array}$ & $\begin{array}{l}\text { Lactate } \\
\text { (mmol/L) }\end{array}$ & $\begin{array}{c}\text { Pyruvate } \\
(\mu \mathrm{mol} / \mathrm{L})\end{array}$ & $\begin{array}{l}\text { Glycerol } \\
(\mu \mathrm{mol} / \mathrm{L})\end{array}$ & $\begin{array}{l}\text { Glutamate } \\
(\mu \mathrm{mol} / \mathrm{L})\end{array}$ & L/P Ratio \\
\hline 2 & 4 & 3 & 5 & 0 & 20.0 & 20.0 & 2.7 & 6.1 & 193.7 & 28.0 & 27.1 & 31.6 \\
\hline 3 & 4 & 3 & 4 & 2 & 18.0 & 21.3 & 1.7 & 10.5 & 146.9 & 577.0 & 66.8 & 71.2 \\
\hline 4 & 3 & 2 & 7 & 0 & 11.0 & 13.7 & 0.6 & 5.7 & 119.8 & 140.0 & 28.2 & 47.2 \\
\hline 6 & 4 & 4 & 5 & 0 & 19.0 & 21.0 & 3.2 & 3.7 & 223.1 & 48.0 & 21.5 & 16.7 \\
\hline 7 & 3 & 2 & 1 & 2 & 26.8 & 34.5 & 2.3 & 4.3 & 120.0 & 72.0 & 60.1 & 35.6 \\
\hline 8 & 4 & 2 & 4 & 0 & 22.6 & 20.8 & 1.5 & 3.8 & 175.0 & 152.3 & 2.3 & 21.9 \\
\hline 9 & 3 & 3 & 3 & 2 & 23.5 & 21.3 & 3.0 & 5.5 & 172.4 & 528.0 & 1.9 & 31.7 \\
\hline
\end{tabular}

* Score at 1-year follow-up. The GOSE scores range from 1 (death) to 8 (excellent recovery).

† CT scan scoring: $0=$ no infarcts; $1=$ infarction in a single hemisphere; $2=$ bilateral infarctions. 

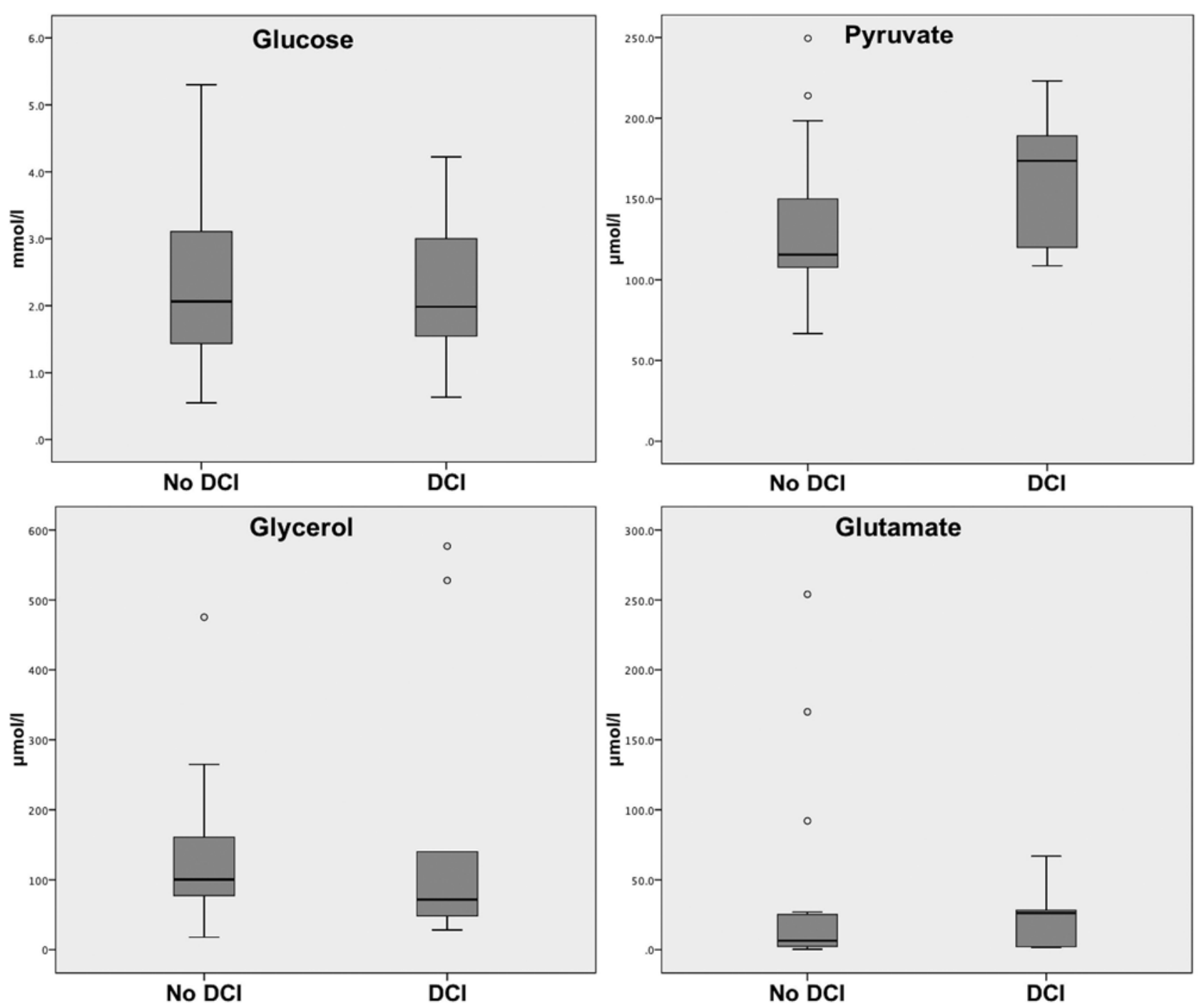

FIG. 5. Box plots of microdialysate glucose, pyruvate, glycerol, and glutamate in patients who later developed DCI and those who did not. No significant differences were observed.

derangement, with high lactate and glutamate levels and $\mathrm{L} / \mathrm{P}$ ratio before DCI symptoms. This is in line with our findings, except for glutamate levels. In patients in whom the characteristic metabolic derangement was not seen, clinical symptoms were related to a vascular territory not monitored with the MD catheter. ${ }^{23}$ In the current study, patients who later developed DCI had significantly higher lactate despite the MD catheter being placed in the right frontal lobe.

Earlier reports have suggested 2 different sources of lactate elevation: one is "hypoxic" and is bad, and the other is "hyperglycolytic" and may be good for the injured brain. ${ }^{2,14}$ Although this theory is in need of further validation, the simultaneous measurements of CBF and lactate and pyruvate in the current study showing low $\mathrm{CBF}$ and high lactate with low pyruvate indicate anaerobic metabolism and energy failure. Pyruvate is an important metabolite that indicates the level of aerobic metabolism of glucose, and low levels have been associated with unfavorable outcome in patients with $\mathrm{SAH} .{ }^{2}$
In the group who did not develop DCI, 3 patients had high lactate levels, but the CBF values were also high in these patients, which could indicate a hyperglycolytic state. There were 3 patients with low $\mathrm{CBF}$ in this group

TABLE 6. Frequency of GOSE scores at 1-year follow-up in patients who later did and did not develop DCl

\begin{tabular}{ccc}
\hline GOSE Score & No DCl & DCl \\
\hline 1 & $3(14)$ & $2(22)$ \\
\hline 2 & $2(10)$ & $0(0)$ \\
\hline 3 & $5(24)$ & $1(11)$ \\
\hline 4 & $5(24)$ & $3(33)$ \\
\hline 5 & $1(5)$ & $2(22)$ \\
\hline 6 & $4(19)$ & $0(0)$ \\
\hline 7 & $0(0)$ & $1(11)$ \\
\hline 8 & $1(5)$ & $0(0)$ \\
\hline
\end{tabular}

Values are expressed as the number of patients (\%). 
who did not develop DCI, and they showed low lactate. This could indicate that low CBF or high lactate per se is not a sufficient indicator of tissue at risk for ischemia and at risk of developing DCI. This is in accordance with previous findings on $\mathrm{CBF}$ and $\mathrm{MD}$ parameters in the injured brain. ${ }^{31}$

One of the limitations of this study is that the person who performed the statistical analysis was not blinded to which patients developed DCI and which did not. However, the $\mathrm{CBF}$ analysis and $\mathrm{MD}$ data extractions were performed before any information was obtained regarding DCI development.

\section{Conclusions}

Our study shows that bedside monitoring of CBF and brain metabolism in SAH is feasible and highly informative. Low $\mathrm{CBF}$, high lactate, and an increased $\mathrm{L} / \mathrm{P}$ ratio were seen early after hemorrhage (Days 0-3) in patients who later developed DCI before any clinical signs had appeared. The clinical significance of these findings must be substantiated in larger studies.

\section{Acknowledgments}

We express our warm gratitude to Johan Bäckander for his excellent work with the Xe-CT examinations.

\section{References}

1. Bergvall U, Steiner L, Forster DM: Early pattern of cerebral circulatory disturbances following subarachnoid haemorrhage. Neuroradiology 5:24-32, 1973

2. Cesarini KG, Enblad P, Ronne-Engström E, Marklund N, Salci K, Nilsson P, et al: Early cerebral hyperglycolysis after subarachnoid haemorrhage correlates with favourable outcome. Acta Neurochir (Wien) 144:1121-1131, 2002

3. Chen HI, Stiefel MF, Oddo M, Milby AH, Maloney-Wilensky E, Frangos S, et al: Detection of cerebral compromise with multimodality monitoring in patients with subarachnoid hemorrhage. Neurosurgery 69:53-63, 2011

4. De Micheli E, Pinna G, Piovan E, Prisco R, Hillered L, Persson L, et al: Monitoring subtle neurometabolic changes in subarachnoid hemorrhage patients using microdialysis: a study on 16 cases. Acta Neurochir Suppl 77:149-153, 2001

5. Diringer MN, Bleck TP, Hemphill JC III, Menon D, Shutter L, Vespa P, et al: Critical care management of patients following aneurysmal subarachnoid hemorrhage: recommendations from the Neurocritical Care Society's Multidisciplinary Consensus Conference. Neurocrit Care 15:211-240, 2011

6. Enblad P, Valtysson J, Andersson J, Lilja A, Valind S, Antoni G, et al: Simultaneous intracerebral microdialysis and positron emission tomography in the detection of ischemia in patients with subarachnoid hemorrhage. J Cereb Blood Flow Metab 16:637-644, 1996

7. Frykholm P, Andersson JL, Långström B, Persson L, Enblad $P$ : Haemodynamic and metabolic disturbances in the acute stage of subarachnoid haemorrhage demonstrated by PET. Acta Neurol Scand 109:25-32, 2004

8. Hillered L, Vespa PM, Hovda DA: Translational neurochemical research in acute human brain injury: the current status and potential future for cerebral microdialysis. J Neurotrauma 22:3-41, 2005

9. Hutchinson PJ, Jalloh I, Helmy A, Carpenter KL, Rostami E, Bellander BM, et al: Consensus statement from the 2014 International Microdialysis Forum. Intensive Care Med 41:1517-1528, 2015
10. Jennett B, Snoek J, Bond MR, Brooks N: Disability after severe head injury: observations on the use of the Glasgow Outcome Scale. J Neurol Neurosurg Psychiatry 44:285293, 1981

11. Kety SS: The theory and applications of the exchange of inert gas at the lungs and tissues. Pharmacol Rev 3:1-41, 1951

12. Meyer JS, Shinohara T, Imai A, Kobari M, Sakai F, Hata T, et al: Imaging local cerebral blood flow by Xenon-enhanced computed tomography-technical optimization procedures. Neuroradiology 30:283-292, 1988

13. Nyberg C, Karlsson T, Hillered L, Ronne Engström E: Metabolic pattern of the acute phase of subarachnoid hemorrhage in a novel porcine model: studies with cerebral microdialysis with high temporal resolution. PLoS One 9:e99904, 2014

14. Oddo M, Levine JM, Frangos S, Maloney-Wilensky E, Carrera E, Daniel RT, et al: Brain lactate metabolism in humans with subarachnoid hemorrhage. Stroke 43:1418-1421, 2012

15. Qureshi AI, Sung GY, Razumovsky AY, Lane K, Straw RN, Ulatowski JA: Early identification of patients at risk for symptomatic vasospasm after aneurysmal subarachnoid hemorrhage. Crit Care Med 28:984-990, 2000

16. Ronne-Engström E, Cesarini KG, Enblad P, Hesselager G, Marklund N, Nilsson P, et al: Intracerebral microdialysis in neurointensive care: the use of urea as an endogenous reference compound. J Neurosurg 94:397-402, 2001

17. Rostami E, Engquist H, Johnson U, Howells T, RonneEngström E, Nilsson P, et al: Monitoring of cerebral blood flow and metabolism bedside in patients with subarachnoid hemorrhage - a Xenon-CT and microdialysis study. Front Neurol 5:89, 2014

18. Ryttlefors M, Howells T, Nilsson P, Ronne-Engström E, Enblad P: Secondary insults in subarachnoid hemorrhage: occurrence and impact on outcome and clinical deterioration. Neurosurgery 61:704-715, 2007

19. Samuelsson C, Hillered L, Enblad P, Ronne-Engström E: Microdialysis patterns in subarachnoid hemorrhage patients with focus on ischemic events and brain interstitial glutamine levels. Acta Neurochir (Wien) 151:437-446, 2009

20. Sarrafzadeh A, Haux D, Küchler I, Lanksch WR, Unterberg AW: Poor-grade aneurysmal subarachnoid hemorrhage: relationship of cerebral metabolism to outcome. J Neurosurg 100:400-406, 2004

21. Sarrafzadeh A, Haux D, Plotkin M, Lüdemann L, Amthauer $\mathrm{H}$, Unterberg A: Bedside microdialysis reflects dysfunction of cerebral energy metabolism in patients with aneurysmal subarachnoid hemorrhage as confirmed by ${ }^{15} \mathrm{O}-\mathrm{H}_{2} \mathrm{O}-\mathrm{PET}$ and ${ }^{18}$ F-FDG-PET. J Neuroradiol 32:348-351, 2005

22. Sarrafzadeh AS, Haux D, Lüdemann L, Amthauer H, Plotkin M, Küchler I, et al: Cerebral ischemia in aneurysmal subarachnoid hemorrhage: a correlative microdialysis-PET study. Stroke 35:638-643, 2004

23. Sarrafzadeh AS, Sakowitz OW, Kiening KL, Benndorf G, Lanksch WR, Unterberg AW: Bedside microdialysis: a tool to monitor cerebral metabolism in subarachnoid hemorrhage patients? Crit Care Med 30:1062-1070, 2002

24. Schmidt JM, Ko SB, Helbok R, Kurtz P, Stuart RM, Presciutti M, et al: Cerebral perfusion pressure thresholds for brain tissue hypoxia and metabolic crisis after poor-grade subarachnoid hemorrhage. Stroke 42:1351-1356, 2011

25. Schulz MK, Wang LP, Tange M, Bjerre P: Cerebral microdialysis monitoring: determination of normal and ischemic cerebral metabolisms in patients with aneurysmal subarachnoid hemorrhage. J Neurosurg 93:808-814, 2000

26. Skoglund K, Hillered L, Purins K, Tsitsopoulos PP, Flygt J, Engquist $\mathrm{H}$, et al: The neurological wake-up test does not alter cerebral energy metabolism and oxygenation in patients with severe traumatic brain injury. Neurocrit Care 20:413426, 2014

27. Solenski NJ, Haley EC Jr, Kassell NF, Kongable G, German- 
son T, Truskowski L, et al: Medical complications of aneurysmal subarachnoid hemorrhage: a report of the multicenter, cooperative aneurysm study. Participants of the Multicenter Cooperative Aneurysm Study. Crit Care Med 23:1007-1017, 1995

28. Sturnegk $\mathrm{P}$, Mellergård $\mathrm{P}$, Yonas $\mathrm{H}$, Theodorsson A, Hillman $\mathrm{J}$ : Potential use of quantitative bedside CBF monitoring (Xe$\mathrm{CT}$ ) for decision making in neurosurgical intensive care. $\mathbf{B r}$ J Neurosurg 21:332-339, 2007

29. Ungerstedt U, Rostami E: Microdialysis in neurointensive care. Curr Pharm Des 10:2145-2152, 2004

30. van Gijn J, Kerr RS, Rinkel GJ: Subarachnoid haemorrhage. Lancet 369:306-318, 2007

31. Vespa P, Bergsneider M, Hattori N, Wu HM, Huang SC, Martin NA, et al: Metabolic crisis without brain ischemia is common after traumatic brain injury: a combined microdialysis and positron emission tomography study. J Cereb Blood Flow Metab 25:763-774, 2005

32. Weir B, Grace M, Hansen J, Rothberg C: Time course of vasospasm in man. J Neurosurg 48:173-178, 1978

33. Yonas H, Darby JM, Marks EC, Durham SR, Maxwell C: $\mathrm{CBF}$ measured by Xe-CT: approach to analysis and normal values. J Cereb Blood Flow Metab 11:716-725, 1991

34. Yonas H, Gur D, Wolfson SK Jr, Good WF, Good BC, Latchaw RE: Xenon-enhanced computerised tomographic cerebral blood flow mapping. Lancet 1:1357, 1984

35. Yonas H, Pindzola RP, Johnson DW: Xenon/computed tomography cerebral blood flow and its use in clinical management. Neurosurg Clin N Am 7:605-616, 1996
36. Yonas H, Sekhar L, Johnson DW, Gur D: Determination of irreversible ischemia by xenon-enhanced computed tomographic monitoring of cerebral blood flow in patients with symptomatic vasospasm. Neurosurgery 24:368-372, 1989

\section{Disclosures}

The authors report no conflict of interest concerning the materials or methods used in this study or the findings specified in this paper.

\section{Author Contributions}

Conception and design: Rostami, Enblad. Acquisition of data: Rostami, Engquist, Howells. Analysis and interpretation of data: Rostami, Johnson, Enblad. Drafting the article: Rostami. Critically revising the article: Rostami, Engquist, Howells, Ronne-Engström, Nilsson, Hillered, Lewén, Enblad. Reviewed submitted version of manuscript: Rostami, Engquist, Howells, Ronne-Engström, Nilsson, Hillered, Lewén, Enblad. Approved the final version of the manuscript on behalf of all authors: Rostami. Statistical analysis: Rostami. Administrative/technical/material support: Engquist, Howells, Ronne-Engström, Nilsson, Hillered, Lewén, Enblad. Study supervision: Rostami, Enblad.

\section{Correspondence}

Elham Rostami, Section of Neurosurgery, Department of Neuroscience, Uppsala University Hospital, SE-751 85 Uppsala, Sweden. email: elham.rostami@neuro.uu.se. 